\title{
An Analysis of the Strategies for Developing Students' Consciousness of Pronunciation and Intonation in College English Teaching Based on the International Communication
}

\author{
Ling Gui \\ ${ }^{1}$ Xin Hua College of Sun Yat-Sen University, Guangzhou, 510520, China
}

\begin{abstract}
Under the background of international communication, college students' English listening and speaking ability has been put forward higher requirements. Improving college students' awareness of pronunciation and intonation is an effective way to solve this problem. The typical problems of college students in pronunciation and intonation are poor pronunciation, inaccurate intonation and inadequate pronunciation and intonation. The formation of these problems is multifaceted, including the lack of students' awareness of pronunciation and intonation, the lack of teachers' awareness of pronunciation and intonation, etc. In terms of strategies to improve students' awareness of pronunciation and intonation, we can adopt the following ways: First, train a group of teachers with awareness of pronunciation and intonation. Secondly, we should infiltrate the training of pronunciation and intonation in classroom teaching. Thirdly, we should combine the teaching of pronunciation and intonation with the traditional English teaching methods. It is believed that through the implementation of these strategies, students can quickly improve their awareness of English pronunciation and intonation, and then help them master English faster and better.
\end{abstract}

\section{Introduction}

In the modern society of economic globalization, academic exchanges and talent exchanges among universities are also increasing day by day. In China, a large number of undergraduate colleges and universities have met with foreign universities, especially on matters concerning international exchange students. On the other hand, nowadays, English education in Colleges and universities in China has entered an ecological background of international communication. College students' English competence will face greater challenges, and it is also one of the key conditions for international communication learning to achieve better results.

At present, the awareness of pronunciation and intonation of college students in English learning is generally weak, and their oral English ability is generally weak. In the whole process of learning English, college students in our country mostly study English reading, cloze filling and English writing with their heads covered, but they neglect the training of English intonation and spoken English seriously. For example, in order to obtain CET-4 or CET-6 certificates, most students memorize a lot of words and learn reading knowledge, but they do not attach importance to the cultivation of listening ability. This leads to the fact that the English skills of college students only stay at the level of "writing", which is far from the level of mastering a language. However, listening and speaking ability are the basic primary abilities of English learners and one of the core of English learning. In 2007, the General Office of the Ministry of Education of China issued the Requirements for College English Teaching, which clearly pointed out the teaching objectives of College English. In College English teaching, we should pay attention to the cultivation of students' comprehensive English application ability, especially listening and speaking ability. The ability to listen and speak enables college students to have a good command of English in the actual workplace and to effectively solve communication problems with foreign friends. Under such circumstances, we can effectively communicate with foreign friends and lay a good foundation for academic research. How can we improve college students' oral and listening abilities? There are many ways to improve students' listening and speaking abilities, but this paper explores the issues related to the cultivation of students' awareness of pronunciation and intonation. It is believed that by adopting suitable teaching and training strategies in College English teaching classes, students' awareness of pronunciation and intonation can be improved, and finally their listening and speaking abilities can be improved. 


\section{Problems in College Students' Pronunciation and Intonation}

\subsection{The problem of non-standard pronunciation}

Among the college students in China, there is a common problem that students' English pronunciation is not standard. The problems caused by poor pronunciation are obvious in two aspects: first, students' poor oral English and communication barriers to a certain extent; second, students' poor listening ability and low listening ability. There is a direct relationship between poor oral pronunciation and poor listening ability. Generally speaking, people who do not have standard oral pronunciation do not know the way people usually pronounce certain words. So when other people talk, they don't understand what it means. But then again, what is the relationship between poor pronunciation and intonation? What role does pronunciation and intonation play in students' English pronunciation? English pronunciation has many characteristics different from Chinese meaning, which requires every one of us to pay special attention to pronunciation. For example, in English reading aloud, there are often techniques such as liaison and weak reading, which lead to different sounds of the same word in different sentences. If the word "the" is followed by a word that begins with a vowel letter, "the" will change its spelling sound. For example, if the letter "a" is preceded by a word that ends with the pronunciation " $t$ ", then the pronunciation is the continuous reading of " $t$ " and "a". Therefore, if you are not familiar with these techniques, you will not be able to understand why the pronunciation is quite different in different places. These problems lead to students' inability to understand the listening part of the topic when they are learning English. Almost half of them depend on strength and half on luck.

\subsection{Intonation inaccuracy}

College students are required to have strong listening and speaking abilities in some English examinations, such as IELTS and TOEFL. Only after passing these highly recognized examinations can college students be identified as having strong English pronunciation and intonation ability. However, college students often fail to meet such requirements. This is due to the fact that college students can not effectively transform their identities in scene simulation so as to produce appropriate pronunciation and intonation. For example, she barely goes shopping on sunday. Shopping and Sunday are the core words and important words to get information. But one of the most important words in this sentence is "barely", which completely negates the meaning of the whole sentence. But in the process of intonation pronunciation, the reader quickly made the "barely" sound. College students with inaccurate pronunciation and intonation may not be able to recognize them. In this way, the meaning of the whole sentence is different.

\subsection{Inadequate pronunciation and tone}

Unlike Chinese syllable timing, English is pronounced with stress. In an English sentence, the number of stresses determines the speed of the sentence, which cannot be understood in Chinese. For sentences with incomplete length, if they contain the same number of stresses, they give the audience a totally different listening experience. In this case, the shorter sentence will read very slowly, but the longer sentence, on the contrary, will read faster. This is the great role of English pronunciation and mood in sentence spelling, and it is also an important difference between Chinese sentences. These tones can also play a very important role in students' listening comprehension. For example, for different types of rhetorical questions, emphasizing sentence patterns, exclamation sentences, etc., the pronunciation of stress reflects completely different auditory feelings, and only those who understand that the pronunciation mood has a great impact on the meaning of sentences can finally grasp the rules of learning English.

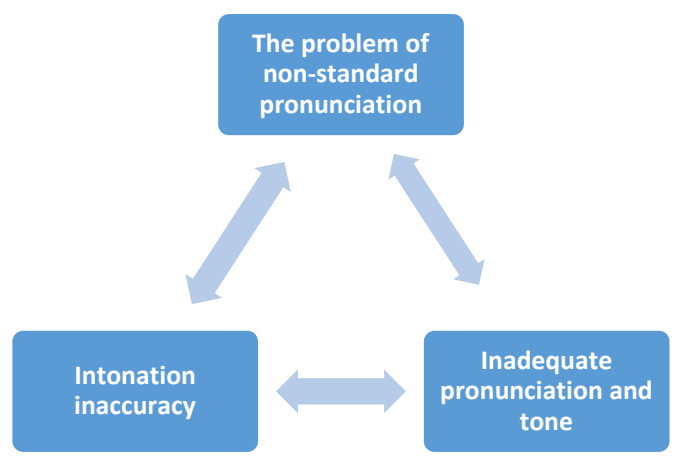

Figure 1. Problems in College Students' Pronunciation and Intonation

\section{The Importance of Pronunciation and Intonation Awareness in Students' English Learning}

\subsection{Pronunciation, Intonation and English Listening and Speaking Ability}

In College English teaching, listening is not only a difficult point for most students, but also an important obstacle for them to improve their English performance. At present, the lack of College Students' listening and speaking ability is closely related to years of compulsory education and high school education. In the previous education process, whether teachers or students, they were very indifferent to the cultivation of pronunciation and intonation. This leads to the fact that students do not enter the world of English pronunciation at all when they receive English education. When college students enter the hall of university, their English level has been greatly tested in the context of international communication ecology, and even they obviously feel that they lack real English ability. College students who lack pronunciation and intonation have great difficulty in both listening training and real English listening and speaking test. What is troubling is that even if college students study in 
a closed way within a certain time, they can not achieve rapid improvement, and they are inculcated with the concept that the improvement of oral English ability is not a matter of overnight. In English learning, listening is a kind of ability to distinguish sounds. This includes many elements, such as monophonic discrimination, rhythm perception and intonation judgment. At the same time, listening ability is also affected by phonetic materials, context, grammar and vocabulary. Therefore, English listening ability is the embodiment of a student's comprehensive English ability, and can not be solved by a single factor.

Oral English competence and listening competence are two different concepts. The former includes the rational expression of pronunciation and intonation, the rational use of vocabulary, and the habitual expression. People have studied Chinese students' pronunciation and intonation patterns and come to the conclusion that Chinese English learners lack pronunciation and intonation awareness while learning English, and rely more on deliberate pauses to express English sentences, which is different from native English learners, who use more pronunciation and intonation group segmentation and pitch reconstruction when using English. Due to the influence of Chinese pronunciation, English learners have the phenomenon of "multiple pronunciation" in their pronunciation. Their spoken English reading lacks the inherent rhythm of English, and there are many phenomena such as stress, weak reading and even stress shifting.

In addition, the intonation is too straight, single, not good at using low-rise, down-rise and other tones are also common phenomena of College students, we must pay attention to them. Therefore, pronunciation and intonation play a very important role in English learning. The cultivation of pronunciation and intonation awareness is an important and fundamental way for students to improve their English ability.

\subsection{Pronunciation, Intonation and English Reading and Writing Ability}

I believe that those who have participated in the English exam know that reading questions are often the common types of questions in the English exam, and also the ones that make many students feel headache. Reading English articles is a complex process of mental and intellectual activities, which needs to mobilize a large number of learners' mental thinking. Now studies have shown that there is a certain correlation between English reading and pronunciation and intonation ability. In medicine, the human brain is located in the left hemisphere and belongs to the area of processing language. It does not directly process information similar to words and images. Therefore, when people read, they have to go through the coordination of the left and right hemispheres, and work together to transform the written symbols into the form of phonetics, and then be processed by the language area of the brain. Therefore, the accuracy of sound image is particularly critical to the fluency and accuracy of reading comprehension. Take the memory of words as an example, when people memorize words, they often spell words according to the pronunciation of words, that is, they can memorize words vividly through the rules of pronunciation of words. This method is very useful. If students can pay attention to the pronunciation of stress, weakness and other pronunciation intonation problems in learning, their ability to remember words will be greatly enhanced, and their reading ability will be correspondingly strengthened.

\section{Strategies for Improving Students' Awareness of Pronunciation and Intonation in College English Classroom Teaching}

Under the educational background of our country, most of the education of English is only for the purpose of examinations. Therefore, it is only to train students to memorize words, learn to read, understand and write essays, etc. without paying special attention to the cultivation of students' pronunciation and intonation ability. Under the cultivation of this model, most students' listening and reading ability is not good enough to achieve the level of normal use of English communication. In the aspect of pronunciation and intonation, quite a number of students can not read and transcribe phonetic symbols correctly. In the study of phonetic knowledge, students only grasp the basic phonetic knowledge, such as vowels and consonants. However, many students have not mastered the knowledge of detonation, continuous reading, weak reading and so on. There is no knowledge about how to cultivate students' awareness of pronunciation and intonation in textbooks or even in various educational institutions. In school teaching, teachers instill in students the knowledge of how to pronounce English, but do not teach children should develop their own pronunciation and intonation ability. As a result, most children are not sure that they should improve their English pronunciation and intonation. This is a great sadness. So why does this happen? The fundamental reason is the lack of teachers' awareness of pronunciation and intonation. We know that teachers are also normal people who grow up from children to adults. Compared with pupils, they are only differences accumulated at the level of cultural knowledge, not differences in the cultural system. When the older generation learns English, they don't even have the awareness that our English teachers should improve their English pronunciation and intonation. Therefore, as teachers, they do not have this awareness, it can be said that consciousness has not yet awakened. Then, in view of these objective situations, the article puts forward the following strategies, hoping to improve students' awareness of pronunciation and intonation in College English classroom teaching.

\subsection{To train a group of teachers with the awareness of pronunciation and intonation}

There is an old saying in China, it is called: A famous teacher makes a good apprentice. Only teachers with excellent professional qualities can cultivate a group of excellent students. Therefore, in order to improve students' awareness of pronunciation and intonation, we 
should pay attention to training a group of teachers with professional competence in this field. When students listen to English courses, they learn the teacher's pronunciation of pronunciation and intonation through deliberate imitation or inadvertent. In order to ensure that students imitate the correct pronunciation and intonation, teachers must have a good professional level in pronunciation and intonation teaching. There are several ways to improve teachers' professional level. Firstly, the education department organizes professional training so that English teachers can participate in the training collectively. In this way, centralized training can be achieved, and a large number of high-quality teachers can be trained. Secondly, through the internal strength of universities, teachers can organize internal training meetings, concentrate on learning, and promote each other's pronunciation and intonation ability. Thirdly, let teachers learn and improve themselves. This way gives full play to teachers' self-motivation and enthusiasm, and is most helpful to the cultivation of teachers' pronunciation and intonation ability. At the same time, teachers can combine the teaching content, selectively choose the place and focus on learning. For example, we can focus on improving our professional competence according to the age differences of the subjects we teach.

\subsection{Permeating the Training of Phonetics and Intonation in Classroom Teaching}

For Chinese students, the accuracy of English pronunciation depends to some extent on their imitation ability. Because students learn English by imitating the teacher's English reading at the beginning of their contact with English subjects. Only after a certain period of repeated imitation, repeated deliberate training, can we finally be familiar with and master the pronunciation of English. Therefore, in the teaching classroom, teachers should begin to deliberately teach students from the perspective of pronunciation and intonation, so that students pay more attention to the differences and help of pronunciation and intonation in learning English. This way is an important way for students to improve their pronunciation and intonation ability. In the classroom, teachers deliberately adopt the teaching method of comparative analysis, so that students can feel the different help of pronunciation and intonation in learning English. In this way, students can feel the same and master the essence of learning pronunciation and intonation more profoundly. If we can really infiltrate the teaching and training of pronunciation and intonation in classroom teaching, we will achieve twice the result with half the effort.

\subsection{Pay attention to the combination of pronunciation and intonation teaching with traditional English teaching methods}

In traditional English teaching, teachers pay attention to the cultivation of grammar, vocabulary, reading comprehension and English writing. Although this training method has some advantages, it is not conducive to the cultivation of students' awareness of pronunciation and intonation. In the cultivation of pronunciation and intonation, students can not memorize words and grasp grammar efficiently without the explanation of traditional knowledge points, so they lack a solid foundation to learn pronunciation and intonation. Therefore, in the new teaching method, the combination of phonetic intonation teaching method and traditional teaching method can give full play to the advantages of both, and it is easier to achieve good teaching results. The research shows that there is a close relationship between pronunciation self-concept, English overall self-concept and English learning achievement. Therefore, the introduction of English pronunciation and intonation teaching in teaching can not only enable students to learn English more scientifically and efficiently, but also reduce learning pressure and increase interest in learning.

\begin{tabular}{l}
\hline 1 \\
To train a group of teachers with the awareness of pronunciation and intonation \\
\hline
\end{tabular}

Figure 2. Strategies for Improving Students' Awareness of Pronunciation and Intonation in College English Classroom Teaching

\section{Conclusion}

Under the ecological background of international communication, how to effectively improve college students' awareness of pronunciation and intonation is an urgent problem to be solved. College teaching classroom plays an important role in this situation. The typical problems of college students in pronunciation and intonation are not standard pronunciation, inaccurate intonation and inadequate pronunciation and intonation. The formation of these problems is multifaceted, including the lack of students' awareness of pronunciation and intonation, the lack of teachers' awareness of pronunciation and intonation, etc. In terms of strategies to improve students' awareness of pronunciation and intonation, we can adopt the following ways: First, train a group of teachers with awareness of 
pronunciation and intonation. Secondly, we should infiltrate the training of pronunciation and intonation in classroom teaching. Thirdly, we should combine the teaching of pronunciation and intonation with the traditional English teaching methods. It is believed that through the implementation of these strategies, students can quickly improve their awareness of English pronunciation and intonation, and then help them master English faster and better.

\section{References}

1. Bassiri M A. Intonation Patterns and Their Place in Teaching Pronunciation for Azeri-Speaking English language Learners[J]. Studies in English Language Teaching, 2013, 13(3):51-65.

2. Fangzhi C. The Teaching of Pronunciation to Chinese Students of English.[C]// Forum. 1998.

3. Setter J. Communicative patterns of intonation in L2 English teaching and learning[J]. Journal of Neuroscience Research, 2005, 9(4):437-444.

4. Li X, Chen J, Yao M, et al. English sentence pronunciation evaluation using rhythm and intonation[C]// International Conference on Systems \& Informatics. 2015.
5. Cockburn B, Fu Z, Hungria A, et al. Stormer-Numerov HDG Methods for Acoustic Waves[J]. Journal of Scientific Computing, 2017.

6. Fu Z , Heuer N, Sayas F J . A non-symmetric coupling of Boundary Elements with the Hybridizable Discontinuous Galerkin method[J]. Computers \& Mathematics with Applications, 2017:S0898122117305278.

7. Yangklang W. Improving English Stress and Intonation Pronunciation of the First Year Students of Nakhon Ratchasima Rajabhat University through

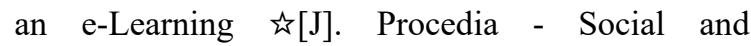
Behavioral Sciences, 2013, 91:444-452.

8. Tuoxin J. Approaches to College English Pronunciation Teaching[J]. Overseas English, 2013(7):20-22.

9. Simpson A. Dialogic teaching in the initial teacher education classroom: "Everyone's Voice will be Heard"[J]. Research Papers in Education, 2016, 31(1):89-106.

10. Fu Z, Heuer N, Sayas F J . Coupling of HDG with a double-layer potential BEM[J]. Mathematics, 2012.

11. Tuoxin J. Influence of Pronunciation and Intonation Imitation Training on Chinese Learners' Spoken English Anxiety[J]. Campus English, 2015(25). 